who fail to do so must understand that they are liable to disqualification.

(2) The Clinical Examination

It is necessary at this stage to emphasise the following recent amendment to the Guidelines which are issued to candidates:

"Prior to their Clinical Examination, candidates should not visit the Hospital to which they have been allocated, either to see patients or for any other purpose relevant to their forthcoming Examination. Any queries concerning this should be addressed to the College of Examinations Officer."

The Court of Electors rightly demands that all candidates should show impeccable standards of behaviour during the College Examinations. Any deviation from these could be a matter of disqualification, not only from the current Examination but also from acceptance as a candidate at any time subsequently.
H. G. MORGAN
A. C. P. Sims
Chief Examiner
Dean

\title{
The training required to provide a psychiatric service for children and adolescents with mental handicaps
}

This report has been written by a Joint Working Party between the Section for the Psychiatry of Mental Handicap and the Child and Adolescent Psychiatry Section which was convened to consider the issues involved in providing a psychiatric service for children and adolescents with mental handicaps.*

\section{Current practice}

To assess current practice and opinion, a postal questionnaire was circulated to 712 members of both Specialist Sections.

Thirty-eight per cent of those working in mental handicap and $49 \%$ of child and adolescent psychiatrists replied, a total of 347 returns.

A quarter of the replies from the psychiatrists in mental handicap showed that they were prepared to offer a service from birth while the rest had a lower age limit which differed widely from 1 to 20 years.

An upper age limit of 17 to 18 years was most commonly operated by child and adolescent psychiatrists with $20 \%$ prepared to see older patients; $22 \%$ took 16 to be the upper age limit though a few were only prepared to see younger children.

Thirty-two per cent of consultant child and adolescent psychiatrists offered a service to children with severe mental handicap but $80 \%$ treated children with mild mental handicap.

Severely handicapped children were treated by $70 \%$ of the psychiatrists in mental handicap but less than $59 \%$ saw those with mild handicap.

-Members of the Working Party: Dr Sheila Hollins (Convenor), Professor Rory Nicol, Professor B. Sacks, Dr Yvonne Wiley (MHPSAC), Dr Tom Berney, and Dr Ann Gath (CAPSAC).
Respondents who did not provide a service themselves were asked who did. Paediatricians were thought by $28 \%$ of both specialities to be filling the gap. It is salutary to note that nine psychiatrists in mental handicap and 22 child psychiatrists replied that there was no psychiatric service for children and adolescents with mental handicap.

\section{Adequacy of current training}

Of those senior registrars/lecturers whose training was primarily in mental handicap, only $23 \%$ felt their training was adequate to offer a service to children with mild learning difficulties and $31 \%$ to treat children with severe learning difficulties. Among the child psychiatry trainees, $62 \%$ were adequately prepared for mild learning difficulties but only $13 \%$ for severe.

Senior registrars being trained in both mental handicap and child psychiatry settings, $7 \%$ of the total, replied that $67 \%$ were satisfied with their training for mild learning difficulties and $60 \%$ for severe learning difficulties. These results point to the advantage of joint training initiatives.

\section{Comments on present provision of service}

Specialists in Mental Handicap and Child and Adolescent Psychiatry provide a complementary service which ideally would be over-lapping but, because of inadequate consultant provision, tend to be overstretched. Some psychiatrists in mental handicap are 'Jacks of all Trades', but others find their administrative role, for example, in hospital resettlement work, 
allows too little time to practise varied clinical skills. Others find that if children were relatively well provided for, there was a risk of neglecting the service for adults.

The continuity with adult services in mental handicap is an advantage but it can be argued that a change of service on approaching adult life is an important developmental stage to emphasise the patient is no longer a child. Adult services also have close liaison with community mental handicap teams about which child psychiatrists were often ignorant. On the other hand, the 1981 Education Act encouraged integration of children with special needs within mainstream education. Child psychiatrists are being increasingly brought into contact with such children. The needs of the other children in the family are better met within mainstream child psychiatry. Some academic psychiatrists with training in child development, neurology and family psychiatry offer diagnostic excellence and very important opportunities for teaching and research. It is usually a tertiary referral service but point asessment may not be helpful on its own unless it brings in the consultant/team who are involved in continuing care. Although neurodevelopmental psychiatry is an integral part of training, it has to be admitted that not every child psychiatrist has an interest or expertise in this client group. (It is, however, a fundamental human right that all children should have access to the same range of health care.)

\section{The type of service required}

Respondents to our survey expressed much uncertainty about what should be provided.

A comprehensive range of high quality services is needed by children with mental handicaps and their families. All children look to the paediatric services for their general and specific health care, assessment and treatment. Few paediatricians have training in child and family psychiatry or in paediatric neurology. In addition, supportive services as distinct from treatment services, and guidance on day to day management are sought by parents. The disabilities are present in children in the longer term and services must be readily accessible and familiar.

\section{District services}

The services that a psychiatrist in each district should provide are:

(i) support to the family of a handicapped child

(ii) provision of health care, in particular treatment of epilepsy

(iii) support of the home/school/other workers who deal with the child and the family (iv) treatment of behavioural or emotional disturbance through behavioural, psychotherapeutic or occasionally drug interventions.

The psychiatrist identified will be included in, or will have access to, a multidisciplinary team which provides continuing support to children with chronic needs including multiple handicap. In most health authorities this team will be a district handicap team, and in others the community mental handicap team.

The children are seen in their own background setting, in their homes or schools, and in co-operation with those catering for other needs in child development clinics.

Any team needs to have a clear definition of its remit so that it does not narrow down to a favoured population, leaving gaps in its service. In particular, it needs to be clear who provides for the autistic child and the child with mild learning difficulties.

Consultation with paediatricians about the range of service provision is essential at both the planning stage and ongoing.

As there is for the non-handicapped population, so there is a case for separate adolescent services.

\section{Special treatment and residential facilities}

There needs to be the opportunity for some behaviourally disturbed children to receive in-patient treatment as well as respite and long term residential care in the community.

Regional units are required for the treatment of very severe behaviour disorders, which appear more commonly in adolescents with mild mental handicap.

\section{Training}

The working party was encouraged by the general willingness of psychiatrists from both child and adolescent psychiatry and mental handicap to work with this group of children. Despite their interest in such children, the majority regarded themselves as ill-equipped to cope with the complex problems. They felt the need of more initial training and of more time to engage with this client group.

The required expertise of the psychiatrist treating children and adolescents with mental handicap is to have the knowledge, clinical skills and attitude to enable him or her to provide a psychiatric service and to take part in teaching, research and service development.

The training needs of the senior registrar are to enable them to acquire: 


\section{(a) Knowledge}

(i) understanding of the range of normal development in childhood and the ability to recognise delay or deviation in development

(ii) the causes of mental handicap and how these may be investigated

(iii) working knowledge of services available to children, including respite care, social service provision and special education. It is also necessary to know what services are available on leaving childhood and entering adult life.

(iv) the assessment of special educational needs

(v) insight into ways in which intellectual disability may contribute to handicap in childhood, may complicate physical and psychiatric disorders in the child and may contribute to family dysfunction.

\section{(b) Skills}

(i) clinical skills to evaluate and treat the psychiatric problems of children with mental handicap and their families.

(ii) the ability to talk to children with mental handicap. Basic understanding of other forms of communication e.g. Makaton vocabulary with signs or symbols.

(iii) principles of behaviour therapy and the modifications that might be required for those of a very limited ability.

\section{(c) Attitudes}

(i) to enable the senior registrar to overcome the common apprehension of working with children with mental handicap

(ii) to understand the way attention to the handicap may obscure recognition of the person, so that such children are not denied their right of access to the full range of services

The essential ingredient of training is active participation in the types of clinical experience that might fulfill these aims and nurture these skills, as found in attachments to:

(i) specialised units and out-patient departments. These are not common and many training schemes will have to do without such an attachment at present

(ii) clinics held in special schools, by child psychiatrists or psychiatrists in mental handicap with school doctors

(iii) Child Development Clinics. Supervision from someone skilled in dealing with psychiatric disturbance must be made available

(iv) Domicillary Services, including early intervention schemes, and participation in multidisciplinary Child Handicap or Community Mental Handicap teams.

\section{Recommendations}

(1) Post-graduate training for psychiatrists, both in mental handicap and child and adolescent psychiatry, working with children with mental handicap should be reviewed urgently. It is suggested that:

Joint training intiatives for senior registrars in both mental handicap and child psychiatry should be encouraged. Trainees with a paediatric background are welcome in both specialities.

A minimum of six months full-time or its equivalent in a child mental handicap placement approved by CAPSAC and MHPSAC is necessary for senior registrars who intend to apply for posts offering a district service in child psychiatry and posts in full age range mental handicap.

CAPSAC have identified a number of centres throughout the UK which exist for special training in the psychiatry of childhood mental handicap. MHPSAC and CAPSAC should review local arrangements and make this component of training essential for continuing approval.

The skills required included those of the neurodevelopmental psychiatrist and point to the need for more academics with these specialist skills and interests.

(2) Manpower implications: Within each district at least one properly trained psychiatrist should be identified to provide an adequate psychiatric service to children and adolescents with mental handicap and their families. Sufficient consultants must be appointed by the districts, as it is essential that such a psychiatrist be provided with the necessary time and resources. Present failures to fill the gap in services to this group are due to the demands of other aspects of the child psychiatry or mental handicap services rather than to reluctance of either to do the work.

It was the view of the working party that such a service could be provided by either a child and adolescent psychiatrist who has acquired the special expertise or by a lifespan mental handicap psychiatrist. Local variation in practice should be recognised within district divisions of psychiatry and a senior psychiatrist identified as responsible for delivering services to children and thus avoiding gaps in provision.

(3) The Joint Working Group should be a permanent feature linking psychiatrists from both sections to address the needs of children with disabilities, and that the group should present clinical innovation and research at College meetings. This working party suggests to both Executive Committees that an Academic Joint Meeting between both the sections of child and adolescent psychiatry and mental handicap psychiatry be convened at the earliest opportunity.

\section{Approved by Council March 1989}

